\title{
Using recreational cannabis to treat insomnia: Evidence from over-the- counter sleep aid sales in Colorado
}

\author{
Jacqueline M. Doremus $^{\mathrm{a}}$, Sarah S. Stith ${ }^{\mathrm{b}, *}$, Jacob M. Vigil ${ }^{\mathrm{c}}$ \\ ${ }^{a}$ California Polytechnic State University, Orfalea College of Business, United States \\ ${ }^{\mathrm{b}}$ University of New Mexico, Department of Economics, United States \\ ${ }^{\mathrm{c}}$ University of New Mexico, Department of Psychology, United States
}

\section{A R T I C L E I N F O}

\section{Keywords:}

Cannabis

Insomnia

Marijuana

Sleep

\begin{abstract}
A B S T R A C T
This study seeks to understand whether people substitute between recreational cannabis and conventional overthe-counter (OTC) sleep medications. UPC-level grocery store scanner data in a multivariable panel regression design were used to compare the change in the monthly market share of sleep aids with varying dispensarybased recreational cannabis access (existence, sales, and count) in Colorado counties between 12/2013 and 12/ 2014. We measured annually-differenced market shares for sleep aids as a portion of the overall OTC medication market, thus accounting for store-level demand shifts in OTC medication markets and seasonality, and used the monthly changes in stores' sleep aid market share to control for short-term trends. Relative to the overall OTC medication market, sleep aid market shares were growing prior to recreational cannabis availability. The trend reverses (a $236 \%$ decrease) with dispensary entry $(-0.33$ percentage points, 95\% CI -0.43 to -0.24 , $\mathrm{p}<0.01$ ) from a mean market share growth of $0.14 \pm 0.97$. The magnitude of the market share decline increases as more dispensaries enter a county and with higher county-level cannabis sales. The negative associations are driven by diphenhydramine- and doxylamine-based sleep aids rather than herbal sleep aids and melatonin. These findings support survey evidence that many individuals use cannabis to treat insomnia, although sleep disturbances are not a specific qualifying condition under any U.S. state-level medical cannabis law. Investigations designed to measure the relative effectiveness and side effect profiles of conventional OTC sleep aids and cannabis-based products are urgently needed to improve treatment of sleep disturbances while minimizing potentially serious negative side effects.
\end{abstract}

\section{Introduction}

About $50 \%$ of the adult population in the United States (US) experiences sleeping problems, with the highest rates among women and older people, ${ }^{1-4}$ and other socio-demographic subgroups (e.g., college students). ${ }^{5}$ Sleep disturbances including insomnia, short or long sleep, and sleep apnea not only create economic burdens on society in terms of medical costs and lost productivity, ${ }^{6-8}$ but are well-established risk factors for mental and physical health conditions, including depression, ${ }^{9,10}$ cognitive impairment, ${ }^{11,12}$ chronic pain, ${ }^{13}$ obesity, vascular diseases, ${ }^{14}$ and overall mortality. ${ }^{15,16}$ Sleep disorders are typically treated with cognitive and behavioral therapies and/or prescription pharmaceuticals, namely anti-depressants, benzodiazepines, gammaaminobutyric acid (GABA) medications, and anti-psychotics, each with their own set of side effects, risk profiles, and dangerous drug interactions. ${ }^{17-19}$ Over-the-counter (OTC) medications including antihistamines (e.g., diphenhydramine and doxylamine), melatonin (available in natural and synthetic forms), and natural products like valerian, are generally believed to be a safer alternative, but tend to be less efficacious, can carry negative side effects (e.g., headaches, confusion, agitation) including vascular disturbances, and in the case of diphenhydramine, are generally not recommended for older people. ${ }^{2,20-25}$ For example, chronic use of sedating antihistamines such as diphenhydramine can increase mortality among the elderly and this medication together with all hypnotics are in Beer's list of medications contraindicated for geriatric population. ${ }^{26}$ Current risks and limitations of treating sleep disturbances with conventional pharmaceutical medications have created the opportunity for alternative therapies to

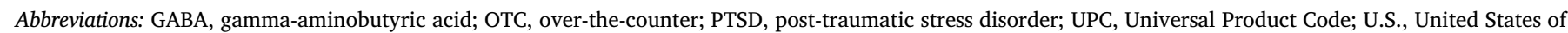
America

* Corresponding author at: University of New Mexico, Department of Economics, 1 University of New Mexico, MSC03 3060, Albuquerque, NM, 87131-0001, 505277-5304, United States.

E-mail addresses: jdoremus@calpoly.edu (J.M. Doremus), ssstith@unm.edu (S.S. Stith), vigilj@unm.edu (J.M. Vigil). 
compete for consumer spending, including cannabis, which is becoming increasingly popular and accessible through state-legal medical and recreational dispensaries across the US.

This study uses retail scanner data to measure the effect of recreational cannabis access on sales of OTC sleep aids in Colorado between $12 / 2013$ and $12 / 2014$. Colorado is an ideal environment for assessing the impact of cannabis on OTC medications due to heterogeneity in the timing and extent of recreational cannabis access across counties and the pre-existing and relatively mature medical cannabis program. We focus on the impact of recreational dispensaries on OTC sleep aid medications because recreational dispensaries enabled the general public to legally use cannabis for improving sleep. Pre-existing medical programs throughout the US (including those in Colorado) do not include sleep disturbances as a specific authorized condition, although some regions (e.g., Washington, DC, but not Colorado) do allow providers to refer individuals with any severe, debilitating condition. However, severe, debilitating sleep disorders are unlikely to be treated with OTC sleep aids, making the population affected by recreational access likely much larger than that affected by medical dispensary access alone. Using a quasi-experimental difference-in-differences regression approach to compare market share growth in OTC sleep aids in counties pre- and post-recreational dispensary entry, we examine the research questions: 1 ) Is access to recreational cannabis via dispensaries associated with changes in purchases of OTC sleep aids? and 2) Does this association differ by category of OTC sleep aid, i.e., pharmaceutical (diphenhydramine and doxylamine) and supplements (melatonin and herbal products)? During the period of our data sample (2012 to 2014), the U.S. market for OTC sleep aids grew more than $37 \%$ from $\$ 570 \mathrm{M}$ to $\$ 780 \mathrm{M}$ in inflation-adjusted dollars. ${ }^{27}$ However, based on previous research showing legal access to medical cannabis reduces the use of multiple scheduled prescription medications, including those used for treating pain and sleep disorders, ${ }^{28-30}$ we hypothesize that recreational cannabis access reduces the market for OTC sleep aids.

\section{Methods}

\subsection{Data}

We extracted data on the OTC medication market from retail scanner data supplied by Nielsen through the Kilts Center for Marketing. The Nielsen data cover $50 \%$ of grocery store commodity volume, $32 \%$ of mass merchandiser sales (e.g., Target), and $1-2 \%$ of liquor and convenience stores. The retail scanner data include all product sales as recorded by check-out scanners for the stores in the Nielsen sample, with the underlying unit of observation the individual product-level Universal Product Code (UPC) data (sales and units), including encoded store identifiers. Nielsen does not report specific product ingredients. The underlying data used in our main analysis includes all stores with non-zero monthly unit sales of any OTC sleep aids for all months between 11/2012 and 12/2014. This restriction ensures that we study stores that consistently stock and sell sleep aids. For our category analysis, we used online manufacturer descriptions to identify active ingredients and group our variables into two product categories: supplements (herbal products and melatonin) and pharmaceuticals (diphenhydramine and doxylamine.) Our category sample includes all stores with positive sales of both of the product categories, supplements and pharmaceuticals, for all months in our sample period.

\subsection{Measures}

For our main outcome variable, the annual growth in monthly OTC sleep aids market share, we begin by dividing unit sales of OTC sleep aids by unit sales of all OTC medications for each store for each month between $11 / 2012$ and $12 / 2014$. Using market shares rather than raw sales allows us to incorporate the size of a store's overall market for OTC medications into our outcome variable, a common approach for estimating population-level effects using Nielsen data. ${ }^{31}$ (Required disclaimer: All results are "calculated (or derived) based on data from The Nielsen Company (US), LLC and marketing databases provided by the Kilts Center for Marketing Data Center at The University of Chicago Booth School of Business.") This also avoids conflating shifts in demand for OTC sleep aids with shifts in demand for all OTC medications. For our category analysis, we calculate the market shares by active ingredient group relative to the overall market for OTC sleep aids, leaving us with two observations (one for pharmaceuticals; one for supplements) for each store-month.

We then adjust our market share measures to account for seasonality by subtracting the market share in a given month-year from the market share in the same month the prior year, so that our outcome variable uses data from $11 / 2012-12 / 2014$ to measure the market share growth in OTC sleep aids between $12 / 2013$ to $12 / 2014$. We also include the month-to-month lag of market share growth as an independent variable in order to account for store-level short-term trends stimulated by, for example, temporary changes in display location or neighborhood promotional circulars. For our main analysis of overall sleep aids, 587 stores with 13 month-level observations per store were analyzed, resulting in a total of 7631 store-months. Including only store-months with product sales of both sub-categories of sleep aids leaves 410 stores (due primarily to some stores not selling the supplements category of products every month) and 10,660 store-productlevel observations. Revenues and prices are in nominal U.S. dollars.

Our exposure variable is county-level recreational cannabis access by month. Recreational cannabis became legally available for purchase from dispensaries in Colorado on $1 / 1 / 2014$. Unlike at medical cannabis dispensaries, which first opened in Colorado on 6/7/2010, recreational cannabis can be purchased without a doctor's referral, essentially overthe-counter. Monthly dispensary access varied during this time from 0 , including some counties (and cities) that banned the sale of recreational cannabis, to a maximum of 101 in Denver County. We use three measures of recreational cannabis access: the existence of any recreational dispensaries, recreational cannabis sales, and the total number of recreational dispensaries in each county in each month as reported by the Colorado Department of Revenue. ${ }^{32}$ Dispensary zip codes were matched to counties using the US Department of Housing and Urban Development's zip code-county crosswalk for the first quarter of 2014. The Colorado Department of Revenue reports county-level recreational and medical cannabis sales based on tax returns filed by Colorado dispensaries, which we categorized as $\$ 0$ sales, sales of $\$ 1$ to $\$ 500,000$, and sales over $\$ 500,000$. Confidentiality exceptions exist for counties with fewer than three recreational cannabis dispensaries or if one dispensary accounts for more than $80 \%$ of reported sales for that countymonth. We code these counties in the $\$ 1$ to $\$ 500,000$ category. Monthly county-level recreational cannabis access was matched with store market share data on the basis of each store's county, as reported in the Nielsen data. Descriptive statistics for all variables are shown in Table 1. Fig. 1 shows the expansion of recreational dispensary access across Colorado counties between 12/2012 and 12/2014.

\subsection{Statistical analysis}

We used ordinary least squares regressions to analyze the association between recreational cannabis access and OTC sleep aids market share growth, regressing the OTC sleep aids market share growth on three county-level measures of recreational cannabis access: existence of any recreational cannabis dispensary; recreational cannabis sales ( $\$ 0, \$ 1-500,000$, or greater than $\$ 500,000$ ); and the number of recreational cannabis dispensaries active that month. For our analysis by sleep aid category, we examine the interaction between an indicator variable for the supplement category with our measures of recreational cannabis access to estimate the differential association of access on supplements' market share growth relative to its association with market share growth in the pharmaceutical product category. 
Table 1

Descriptive Statistics for Regression Samples.

\begin{tabular}{|c|c|c|c|c|}
\hline & Mean & SD & Minimum & Maximum \\
\hline \multicolumn{5}{|c|}{$\begin{array}{l}\text { Panel A: Store-Level OTC Sleep Aids Market Information } \\
\text { (587 stores, } 7631 \text { store-months) }\end{array}$} \\
\hline Any Dispensary & 0.69 & 0.46 & 0.00 & 1.00 \\
\hline Number of Dispensaries & 14.41 & 30.79 & 0.00 & 119.00 \\
\hline Revenue $=\$ 0$ & 0.43 & 0.50 & 0.00 & 1.00 \\
\hline Revenue $\$ 1-500 \mathrm{~K}$ & 0.19 & 0.39 & 0.00 & 1.00 \\
\hline Revenue $\$ 500 \mathrm{~K}+$ & 0.38 & 0.49 & 0.00 & 1.00 \\
\hline Sleep Aids Sales (units) & 94.38 & 73.52 & 1.00 & 613.00 \\
\hline OTC Medication Sales (units) & 2,841 & 2,150 & 181 & 19,227 \\
\hline $\begin{array}{l}\text { Sleep Aids Share of OTC } \\
\text { Market x } 100\end{array}$ & 3.41 & 1.10 & 0.21 & 18.57 \\
\hline $\begin{array}{l}\text { Sleep Aids Market Share } \\
\text { Growth x } 100\end{array}$ & 0.14 & 0.97 & -10.27 & 12.66 \\
\hline $\begin{array}{l}\text { One Month Lagged Market } \\
\text { Share Growth x } 100\end{array}$ & 0.18 & 0.97 & -7.36 & 12.66 \\
\hline Medical Cannabis Patients & 8,917 & 6,411 & 31 & 20,186 \\
\hline Population & 397,635 & 237,185 & 3,537 & 665,052 \\
\hline $\begin{array}{l}\text { Medical Cannabis Patients/ } \\
\text { Population (\%) }\end{array}$ & 2.12 & 0.66 & 0.68 & 4.85 \\
\hline Sleep Aids Price (\$) & 7.02 & 2.27 & 1.34 & 13.25 \\
\hline Sleep Aids Price Growth (\$) & 0.06 & 0.85 & -6.47 & 4.44 \\
\hline Number of Sleep Aids UPCs & 45.79 & 24.91 & 1.00 & 136.00 \\
\hline $\begin{array}{l}\text { Growth in Sleep Aids UPCs } \\
\quad \text { (UPCs) }\end{array}$ & 2.77 & 9.42 & -38.00 & 50.00 \\
\hline \multicolumn{5}{|c|}{$\begin{array}{l}\text { (410 stores, } 820 \text { store-product categories, } 5330 \text { store-months per product } \\
\text { category) }\end{array}$} \\
\hline \multicolumn{5}{|l|}{ Pharmaceutical Sleep Aids } \\
\hline Sales (units) & 108.40 & 64.77 & 5.00 & 551.00 \\
\hline Market Share x 100 & 87.39 & 6.91 & 33.33 & 99.29 \\
\hline Market Share Growth x 100 & 2.94 & 7.05 & -39.70 & 41.96 \\
\hline \multicolumn{5}{|l|}{ Supplement Sleep Aids } \\
\hline Sales (units) & 13.79 & 8.88 & 1.00 & 80.00 \\
\hline Market Share & 12.61 & 6.91 & 0.71 & 66.67 \\
\hline Market Share Growth & -2.94 & 7.05 & -41.96 & 39.70 \\
\hline
\end{tabular}

Notes: Total Observations refers to store-months in Panels A and store-productcategory-months in Panel B. (In Panel B, each store-month has one observation for pharmaceutical sleep aids and one observation for supplements.) Revenue variables are $\{0,1\}$ variables for whether a store is in a county that falls into that revenue category. Sleep Aids Market Share refers to sleep aids sales divided by total over-the-counter medication sales. Sleep Aids Market Share Growth subtracts the current month's sleep aids market share from the sleep aids market share in the same month one year prior to difference out store-specific seasonality. (Growth in Price per Dose and Growth in Number of UPCs are constructed similarly by subtracting the value from that month in the prior year.) Market shares are multiplied by 100 to facilitate interpretation of percentage point changes in the regression results. The underlying data range from 11/ 2012 through 12/2014.

In all our regressions, we control at the store-level for factors likely to affect demand for OTC sleep aids, including growth in the number of varieties of sleep aids within a product line (e.g., new dosages or numbers of doses in a package), price growth (per product and per dose in our store- and store-product-level analyses, respectively), and the lagged monthly market share growth in order to control for monthly changes in unobserved factors that affect product sales besides price and product variety. At the county-level, we control for population and the size of the medical cannabis market using the number of medical cannabis patients as a percent of a county's 2010 population. Product characteristics are based on the underlying Nielsen data, medical cannabis patient information is from the Colorado Department of Public Health's Medical Cannabis Registry, and county-level population data are from U.S. Census Bureau. In each analysis, we also create separate intercepts (fixed effects) to control for time-invariant effects, i.e., factors that do not change over our sample period. We include store-level intercepts for our main analysis and store-category intercepts, i.e. storepharmaceutical or store-supplement, for our category analysis. We cluster our standard errors at the store level to control for heteroskedasticity and within-store error correlation.

In Panel A of Fig. 2, we provide graphical support for the parallel trends assumption underlying our difference-in-differences estimation approach and the need to adjust for seasonality. Panel B of Fig. 2 depicts the stability over time of the denominator of our OTC sleep aids market share, OTC medications.

Because Denver is such a clear outlier, due to its large number of recreational dispensaries and associated tourism, and hence the proportion of individuals likely contributing to recreational cannabis purchases but not necessarily to local OTC medication purchases, we rerun our regressions omitting Denver as a robustness check. All analyses were conducted using Stata 14.2.

\section{Results}

Fig. 3 shows that before a dispensary opens, sleep aid market share growth was flat, but after entry the growth declined with each month. (Supplementary Appendix Fig. SA1 indicates that the sleep aids market share continued to decline with each additional dispensary.) Similarly, our regression results in Panel A of Table 2 show that sleep aid market share growth decreased by $236 \%$ or 0.33 percentage points $(95 \%$ CI -0.43 to $-0.24, p<0.01$ ) after dispensary entry (from a mean market share growth of $0.14 \pm 0.97$, measured from 1 to 100) and this negative association grew with the size of the recreational cannabis market. Comparing across product categories in Table 2, Panel B, we find that supplement market share growth increases with dispensary entry relative to that of pharmaceutical sleep aids, i.e., that decreases in the pharmaceutical market share growth drive the decrease in overall sleep aid market share growth following access to recreational cannabis. Our robustness check omitting Denver yields a similar pattern of results as reported in Supplemental Appendix Table SA1.

\section{Discussion}

Quality sleep is necessary for optimal mental and physical health, behavioral functioning, and wellbeing, and yet sleep disorders are pervasive in industrialized societies. ${ }^{2-5}$ Conventional OTC pharmaceutical sleeping aids have limited effectiveness, ${ }^{33,34}$ with $80 \%$ of consumers reporting residual effects (e.g., drowsiness, concentrating and memory impairments) that can contribute to broader behavioral disturbances (e.g., work absenteeism, non-work activities impairment). ${ }^{35}$ Consumers of conventional sleeping medications report experimenting with an average of four types of sleep aids in the past year. ${ }^{26}$ With nearly $50 \%$ dissatisfaction rates, ${ }^{36}$ consumers may welcome alternative medication options. Our results show that the market share growth for sleep aids shrank with the entry of recreational cannabis dispensaries by more than $200 \%$ relative to the mean market share growth in our sample, and the strength of the association increased with each subsequent dispensary. In particular, cannabis appears to compete favorably with OTC sleep aids, especially those containing diphenhydramine and doxylamine, which constitute $87.4 \%$ of the market for OTC sleep aids. Cannabis access may also be associated with an increased preference for more natural sleep aids, such as melatonin and valerian.

Our results are consistent with evidence that legal access to medical cannabis is associated with reductions in Scheduled II-V prescription medications (e.g., opioids and sedatives), many of which may be used in part as sleep aids. ${ }^{28-3037}$ Prescription sleep aids, namely anti-depressants (e.g., trazodone, amitriptyline, and doxepin), benzodiazepines (e.g., diazepam and lorazepam), GABA medications (zolpidem and eszopiclone), and anti-psychotics (aripiprazole, olanzapine, quetiapine and risperidone) come with practical and significant clinical drawbacks. ${ }^{17-19}$ For example, while tricyclic antidepressants and benzodiazepines can improve certain sleep outcomes (e.g., latency to falling asleep), they can also cause somnolence and slow-wave interference (e.g., rapid eye movement [REM] sleep), and long-term use is 


\section{Roll Out of Dispensaries in Colorado}
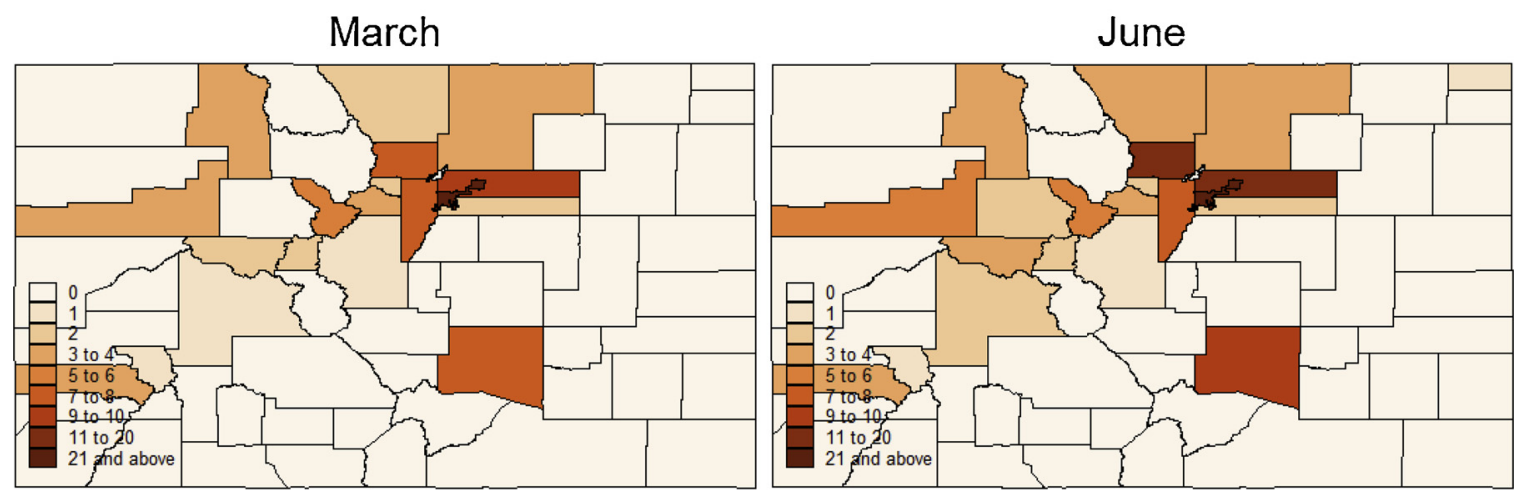

\section{September}
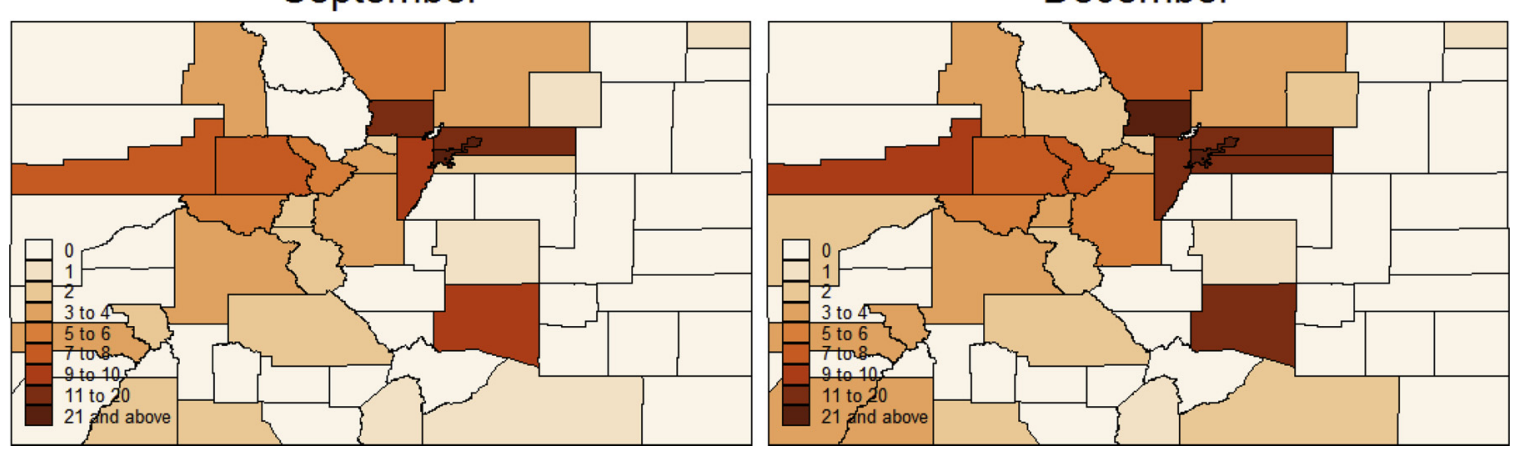

Fig. 1. Dispensary Entry in Colorado 1/2014 to 12/2014.

Notes: The maps show the increase in recreational cannabis access over time as dispensaries entered counties across Colorado.

associated with a heightened risk for neurodegenerative disorders (e.g., Alzheimer's disease), malignancy, and death by suicide and accidental poisoning. ${ }^{38-41}$

For the first time, we show a statistically significant negative association between recreational access to cannabis and OTC sleep aid sales, suggesting that at least some recreational purchasers are using cannabis for therapeutic rather than recreational purposes. Additionally, despite a lack of direct clinical evidence on the effectiveness of self-managed cannabis as a sleep aid, our results indicate that enough individuals are switching from OTC sleep aids to recreational cannabis that we can identify a statistically significant reduction in the market share growth of OTC sleep aids in conjunction with access to recreational cannabis using a statistically conservative county-month-level treatment variable and a quasi-experimental research design. Recreational cannabis access likely increases cannabis demand in general for several economic and medical reasons, such as decreased transaction costs, reduced stigma, and cannabis tourism. Such access could increase specifically medicinal use of cannabis if, as our results suggest, cannabis improves sleep disorders typically treated with OTC sleep aids. Sleep improvement, possibly alongside improvements in primary symptom management associated with sleep disturbances such as pain and anxiety, could partially explain why cannabis is the most widely used substance in the U.S. ${ }^{42}$ Substitution of cannabis for conventional sleep aids may also reflect a broader trend toward "natural" remedies as reflected in increased market share growth for supplement-based OTC sleep aids relative to diphenhydramine- and doxylamine-based sleep aids.

The plant has been investigated as a potential treatment for a range of medical conditions from post-traumatic stress disorder to cancer, with the most consistent support for the treatment of chronic pain, epilepsy, and spasticity. ${ }^{42}$ The current results are consistent with survey-based studies showing increasing use of cannabis for improving sleep among patient populations with disparate diagnoses (e.g., posttraumatic stress disorder (PTSD), Parkinson's disease $)^{43,44,45}$ and a mobile app-based study that measured the real-time effectiveness of using Cannabis flower for treating insomnia. ${ }^{46}$ Any potential therapeutic benefits of cannabis use should, however, be weighed against the risks of using cannabis as a sleep aid. While clinical trials have shown that cannabis improves sleep in the short term, ${ }^{42}$ the risks of long-term use are unknown. Other sleep medications carry risks of dose escalation and dependence, and a similar risk of increased tolerance to the somnolent effects of cannabis and a subsequently increased risk of experiencing cannabis withdrawal syndrome, often characterized by disturbed sleep, may also occur. Regular cannabis use for sleep, and any rebound withdrawal symptoms when use is ceased, could promote continued cannabis use and increase the likelihood of developing cannabis dependence. Unfortunately, due to cannabis' continued Schedule I status and associated barriers to conducting medical cannabis research, ${ }^{47}$ no practical, naturalistic investigations have been completed on how patient-managed phytocannabinoid consumption affects long term sleep prognosis or even discrete mechanisms (e.g., ventrolateral preoptic nucleus activation, memory consolidation) and other basic characteristics (e.g., sleep stages, circadian rhythm) involved in normal and aberrant sleep patterns.

Our study has limitations. We assume that OTC sleep aids are not commonly used for recreational purposes and that while cannabis substitutes for OTC sleep aids, the marginal benefit over locally obtained OTC sleep aids is insufficient for individuals to travel a significant distance to purchase cannabis products. If enough individuals are willing to travel to the next county to obtain cannabis rather than use an OTC sleep aid, our study may be underestimating the impact of recreational cannabis access on OTC sleep aid markets. Alternatively, we could be overestimating the effect of recreational cannabis access if consumers are shifting towards purchasing sleep aids, but not other OTC medications, from stores not in our data at the same time a dispensary opens. However, the continued reductions in sleep aid market share growth with the entry of additional recreational cannabis stores 

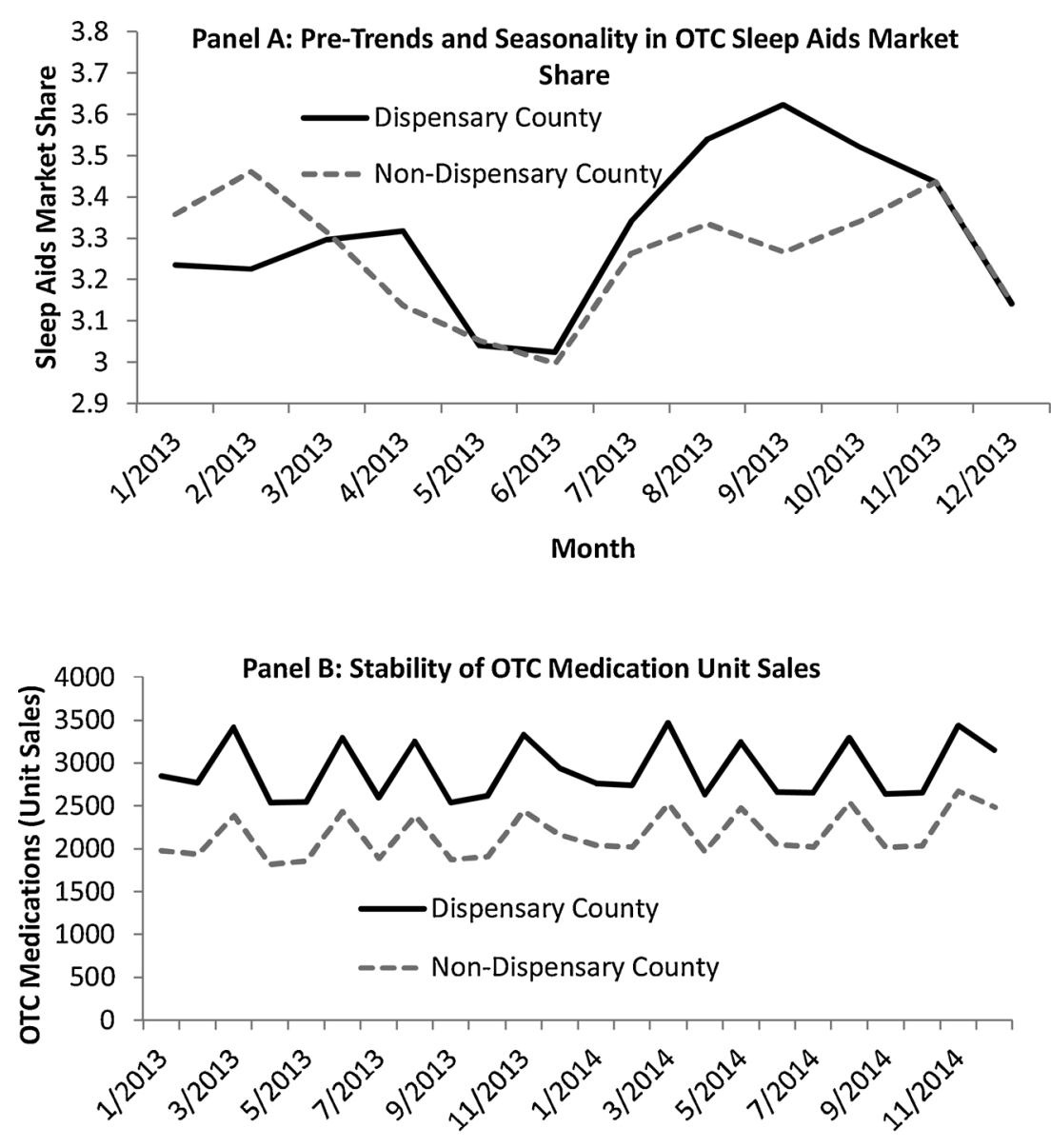

Month

Fig. 2. Testing Assumptions.

Notes: We differentiate between counties in which a dispensary never opened (Non-Dispensary County) and counties in which at least one dispensary entered between 1/2014 and 12/2014 (Dispensary County). Panel A graphs the mean OTC sleep aids share (relative to all OTC medication unit sales) for all stores in our sample by month during 2013 by type of county. Panel B shows mean OTC Medication Unit Sales from 1/2013 through 12/2014 by type of county.

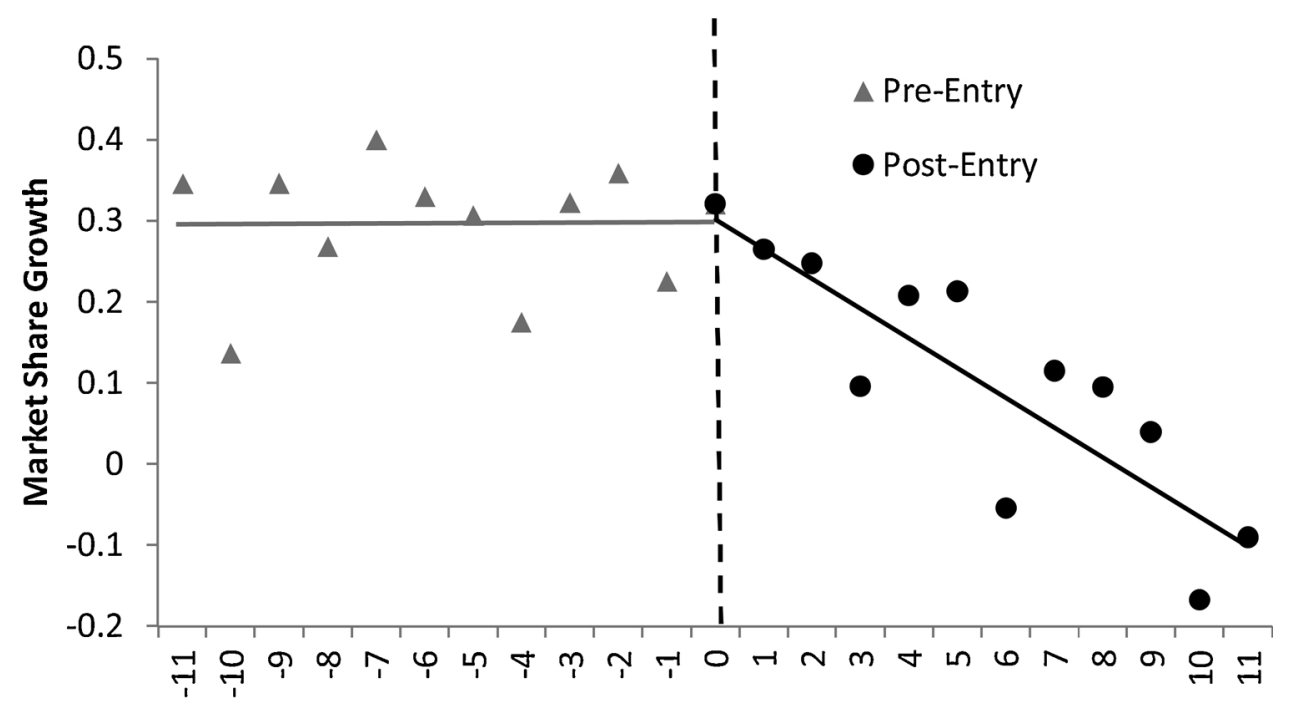

Months Relative to Dispensary Entry at Time $=0$
Fig. 3. OTC Sleep Aids Market Share Growth Pre- and Post-First Dispensary Entry. Notes: Market Share Growth refers to the annual growth in monthly market share of OTC sleep aids relative to the market for all OTC medications (in unit sales). The scatter plot shows the average market share growth for each month relative to the month of dispensary entry and include only data from counties in which at least one dispensary opened by $12 /$ 2014. We also show trend lines fitted to the scatter plot by period, pre- and post-entry. supports that recreational cannabis access rather than an omitted variable is driving the reduction in sleep aids. It is interesting that total OTC medication sales remained basically unchanged regardless of presence or absence of recreational cannabis dispensaries, likely due to the small sleep aid market space $(<3.7 \%$ market share) relative to the overall OTC medication market. Future research should consider investigating the the overall and relative effects of recreational and medical cannabis access on OTC medication usage, given medical dispensaries operate legally in more states than do recreational dispensaries and existing research suggesting a decline in prescription 
Table 2

Association between Sleep Aids Market Share Growth \& Recreational Cannabis Access.

\begin{tabular}{|c|c|c|c|}
\hline & (1) & $(2)$ & (3) \\
\hline \multicolumn{4}{|c|}{ Panel A: Overall Sleep Aids Market Analysis (587 stores; 7631 store-months) } \\
\hline Any Dispensary & $\begin{array}{l}-0.334 * * * \\
(-0.426 \text { to } \\
-0.241)\end{array}$ & & \\
\hline Revenue $\$ 1-500,000$ & & $\begin{array}{l}-0.242 * * * \\
(-0.315 \text { to } \\
-0.170)\end{array}$ & \\
\hline Revenue $\$ 500,000+$ & & $\begin{array}{l}-0.301 * * * \\
(-0.368 \text { to } \\
-0.235)\end{array}$ & \\
\hline Number of Dispensaries & & & $\begin{array}{l}-0.005^{* * *} \\
(-0.009 \text { to } \\
-0.002)\end{array}$ \\
\hline R-squared & 0.218 & 0.219 & 0.212 \\
\hline \multicolumn{4}{|c|}{$\begin{array}{l}\text { Panel B: Product Category Analysis (820 store-categories; } 10,660 \text { store-category- } \\
\text { months) }\end{array}$} \\
\hline Any Dispensary & $\begin{array}{l}-0.543^{* *} \\
(-1.032 \text { to } \\
-0.054)\end{array}$ & & \\
\hline $\begin{array}{l}\text { Any Dispensary x } \\
\text { Supplement }\end{array}$ & $\begin{array}{l}1.357^{* * *} \\
(0.107-2.607)\end{array}$ & & \\
\hline Revenue $\$ 1-500,000$ & & $\begin{array}{l}-0.656 * * \\
(-1.244 \text { to } \\
-0.069)\end{array}$ & \\
\hline Revenue $\$ 500,000+$ & & $\begin{array}{l}-0.315 \\
(-0.970-0.340)\end{array}$ & \\
\hline $\begin{array}{l}\text { Revenue } \$ 1-500,000 \mathrm{x} \\
\quad \text { Supplement }\end{array}$ & & $\begin{array}{l}1.482^{* *} \\
(0.014-2.951)\end{array}$ & \\
\hline $\begin{array}{l}\text { Revenue } \$ 500,000+x \\
\quad \text { Supplement }\end{array}$ & & $\begin{array}{l}1.520 * * \\
(0.218-2.822)\end{array}$ & \\
\hline Number of Dispensaries & & & $\begin{array}{l}-0.013^{* *} \\
(-0.025 \text { to } \\
-0.001)\end{array}$ \\
\hline Number x Supplement & & & $\begin{array}{l}0.035 \\
(-0.008- \\
0.078)\end{array}$ \\
\hline R-squared & 0.125 & 0.125 & 0.124 \\
\hline
\end{tabular}

Notes: Each column in each panel represents a separate regression. Coefficients from a least squares regression model are reported in line with the corresponding variable with $95 \%$ confidence intervals below. Our outcome variable is the Sleep Aids Market Share Growth, or growth in the market share of sleep aids relative to the overall market for over-the-counter medications. Panel A reports results for the overall sleep aids market and Panel B identifies the differential effect of recreational cannabis access on the supplement category of sleep aids relative to the pharmaceutical category of sleep aids. Observation counts are in store-months in Panel A and store-product category-months in Panel B. Revenue refers to recreational cannabis revenue only. The omitted Revenue category is Revenue $=\$ 0$. All regressions include medical cannabis patients as a \% of population, a previous month-level lag in the market share to control for store-level short-term trends in market shares, growth in prices, growth in the number of UPCs, and population. The top panel includes storelevel indicator variables (store-level fixed effects) and the bottom panel includes store-category indicator variables to control for time-invariant store and store-category characteristics. Growth variables compare the current value of each variable for a given month with the value for that month in the prior year in order to difference out store-specific seasonality. Standard errors are clustered at the store level. $\mathrm{p}<0.01^{* * *}, \mathrm{p}<0.05^{* *}, \mathrm{p}<0.1 *$.

drug use following access to medical dispensaries. ${ }^{28-30}$

In conclusion, recreational cannabis dispensaries greatly increase the number of individuals able to legally treat sleep disorders using cannabis, particularly those with mild to moderate sleep disorders. The apparent use of cannabis as a sleep aid in this study underscores the importance of further medical research regarding its risk-benefit profile and the effectiveness of cannabis as a substitute for prescription sleep aids, which generally entail even greater risks to patients than OTC sleep aids. These issues are particularly important for older people, who tend to experience high rates of sleep disturbances, such as insomnia and sleep-disordered breathing, ${ }^{48}$ and heightened risk for cognitive impairment, dementia, depression, neurodegeneration, and Alzheimer's diseases. ${ }^{10-1338-40}$ Despite the current lack of extensive medical evidence, the market evidence suggests that many consumers may be opting to use cannabis for treating their sleep disturbances.

\section{Funding}

No outside funding was used to support this study.

Dr. Jacob Vigil is the Director of the University of New Mexico's Medical Cannabis Research Fund (MCRF); Drs. Jacqueline Doremus and Sarah Stith are affiliated researchers. The MCRF did not provide funding to support this study.

\section{Declaration of Competing Interest}

Dr. Jacob Vigil is the Director of the University of New Mexico's Medical Cannabis Research Fund (MCRF); Drs. Jacqueline Doremus and Sarah Stith are affiliated researchers. The MCRF did not provide funding to support this study.

\section{Acknowledgements}

Author Contributions: JD, SS and JV conceived the study. JD obtained and managed the data and conducted the analyses. JV and SS drafted the manuscript and SS takes responsibility for the manuscript as a whole. All authors contributed substantially to its intellectual content and revision. We would like to thank Avinandan Chakraborty for research assistance collecting county-level medical marijuana patient data.

Required Disclaimer: "The conclusions drawn from the Nielsen data are those of the researchers and do not reflect the views of Nielsen. Nielsen is not responsible for, had no role in, and was not involved in analyzing and preparing the results reported herein."

\section{Appendix A. Supplementary data}

Supplementary material related to this article can be found, in the online version, at doi:https://doi.org/10.1016/j.ctim.2019.102207.

\section{References}

1. Abraham O, Pu J, Schleiden LJ, Albert SM. Factors contributing to poor satisfaction with sleep and healthcare seeking behavior in older adults. Sleep Health. 2017;3(1):43-48. https://doi.org/10.1016/j.sleh.2016.11.004.

2. Centers for Disease Control. https://www.cdc.gov/sleep/data_statistics.html. (Accessed March, 15, 2018).

3. Ellis JG, Perlis ML, Neale LF, Espie CA, Bastien CH. The natural history of insomnia: Focus on prevalence and incidence of acute insomnia. $J$ Psychiatr Res. 2012;46(10):1278-1285. https://doi.org/10.1016/j.jpsychires.2012.07.001.

4. Ohayon MM. Epidemiology of insomnia: what we know and what we still need to learn. Sleep Med Rev. 2002;6(2):97-111. https://doi.org/10.1053/smrv.2002.0186.

5. Jiang X, Zheng X, Yang J, et al. A systematic review of studies on the prevalence of insomnia in university students. Public Health. 2015;129(12):1579-1584. https://doi. org/10.1016/j.puhe.2015.07.030.

6. Daley M, Morin CM, LeBlanc M, Grégoire JP, Savard J. The economic burden of insomnia: direct and indirect costs for individuals with insomnia syndrome, insomnia symptoms, and good sleepers. Sleep. 2009;32(1):55-64. https://doi.org/10.1016/j. sleep.2008.04.005.

7. Léger D, Bayon V. Societal costs of insomnia. Sleep Med Rev. 2010;14(6):379-389. https://doi.org/10.1016/j.smrv.2010.01.003.

8. Wickwire EM, Shaya FT, Scharf SM. Health economics of insomnia treatments: the return on investment for a good night's sleep. Sleep Med Rev. 2016;30:72-82. https:// doi.org/10.1016/j.smrv.2015.11.004.

9. Baglioni C, Battagliese G, Feige B, et al. Insomnia as a predictor of depression: a metaanalytic evaluation of longitudinal epidemiological studies. $J$ Affect Disord. 2011;135(1-3):10-19. https://doi.org/10.1016/j.jad.2011.01.011.

10. Buysse DJ, Angst J, Gamma A, Ajdacic V, Eich D, Rössler W. Prevalence, course, and comorbidity of insomnia and depression in young adults. Sleep. 2008;31(4):473-480. 
https://doi.org/10.1093/sleep/31.4.473.

11. Lowe CJ, Safati A, Hall PA. The neurocognitive consequences of sleep restriction: a meta-analytic review. Neurosci Biobehav Rev. 2017;80:586-604. https://doi.org/10. 1016/j.neubiorev.2017.07.010.

12. Shi L, Chen S, Ma M, et al. Sleep disturbances increase the risk of dementia: a systematic review and meta-analysis. Sleep Med Rev. 2017;40:4-16. https://doi.org/10. 1016/j.smrv.2017.06.010.

13. Sivertsen B, Krokstad S, Øverland S, Mykletun A. The epidemiology of insomnia: Associations with physical and mental health: the HUNT-2 study. $J$ Psychosom Res. 2009;67(2):109-116. https://doi.org/10.1016/j.jpsychores.2009.05.001.

14. Xie C, Zhu R, Tian Y, Wang K. Association of obstructive sleep apnoea with the risk of vascular outcomes and all-cause mortality: a meta-analysis. BMJ Open. 2017;7:e013983https://doi.org/10.1136/bmjopen-2016-013983.

15. Jike M, Itani O, Watanabe N, Buysse DJ, Kaneita Y. Long sleep duration and health outcomes: a systematic review, meta-analysis and meta-regression. Sleep Med Rev. 2017;39:25-36. https://doi.org/10.1016/j.smrv.2017.06.011.

16. Itani O, Jike M, Watanabe N, Kaneita Y. Short sleep duration and health outcomes: A systematic review, meta-analysis, and meta-regression. Sleep Med. 2017;32:246-256. https://doi.org/10.1016/j.sleep.2016.08.006.

17. Ballesio A, Raisa M, Aquino J, et al. The effectiveness of behavioural and cognitive behavioural therapies for insomnia on depressive and fatigue symptoms: a systematic review and network meta-analysis. Sleep Med Rev. 2018;37:114-129. https://doi. org/10.1016/j.smrv.2017.01.006.

18. Morin CM, Benca R. Chronic insomnia. Lancet. 2012;379(9821):1129-1141. https:// doi.org/10.1016/S0140-6736(11)60750-2.

19. van Straten A, van der Zweerde T, Kleiboer A, Cuijpers P, Morin CM, Lancee J. Cognitive and behavioral therapies in the treatment of insomnia: a meta-analysis. Sleep Med Rev. 2017;38:3-16. https://doi.org/10.1016/j.smrv.2017.02.001.

20. Auld F, Maschauer EL, Morrison I, Skene DJ, Riha RL. Evidence for the efficacy of melatonin in the treatment of primary adult sleep disorders. Sleep Med Rev. 2017;34:10-22. https://doi.org/10.1016/j.smrv.2016.06.005.

21. Albert SM, Roth T, Toscani M, Vitiello MV, Zee P. Sleep health and appropriate use of OTC sleep aids in older adults-Recommendations of a Gerontological Society of America Workgroup. Gerontologist. 2017;57(2):163-170. https://doi.org/10.1093/ geront/gnv139.

22. Bent S, Padula A, Moore D, Patterson M, Mehling W. Valerian for sleep: a systematic review and meta-analysis. Am J Med. 2006;119(12):1005-1012. https://doi.org/10. 1016/j.amjmed.2006.02.026.

23. Pragst F, Herre S, Bakdash A. Poisonings with diphenhydramine - a survey of 69 clinical and 55 death cases. Forensic Sci Int. 2006;161:189-197 10.16/j.forsciint.2006.01.019.

24. Radovanovic D, Meier PJ, Guirguis M, Lorent JP, Kupferscchmidt H. Dose-dependent toxicity of diphenhydramine overdose. Hum Exp Toxicol. 2000;19:489-495. https:// doi.org/10.1191/096032700671040438.

25. Sateia MJ, Buysse DJ, Krystal AD, Neubauer DN, Heald JL. Clinical practice guideline for the pharmacologic treatment of chronic insomnia in adults: an American Academy of Sleep Medicine clinical practice guideline. $J$ Clin Sleep Med. 2017;13(2):307-349. https://doi.org/10.5664/jcsm.6470.

26. American geriatrics society 2015 beers criteria update expert panel. American geriatrics society 2015 updated beers criteria for potentially inappropriate medication use in older adults. J Am Geriatr Soc. 2015;63(11):2227-2246.

27. Mintel. OTC Sleep Aids, US, March 2017. Retrieved April 1, 2017 from Mintel Reports database.

28. Bradford AC, Bradford WD. Medical marijuana laws reduce prescription medication use in Medicare Part D. Health Aff. 2016;35(7):1230-1236. https://doi.org/10.1377/ hlthaff.2015.1661.

29. Stith SS, Vigil JM, Adams IM, Reeve AP. Effects of legal access to cannabis on scheduled II-V drug prescriptions. J Am Med Dir Assoc. 2018;19:59-64. https://doi. org/10.1016/j.jamda.2017.07.017 e1.

30. Vigil JM, Stith SS, Adams IM, Reeve AP. Associations between medical cannabis and prescription opioid use in chronic pain patients: a preliminary cohort study. PLoS One. 2017;12(11):e0187795https://doi.org/10.1371/journal.pone.0187795.

31. Pandya SS, Venkatesan R. French roast: consumer response to international conflictevidence from supermarket scanner data. Rev Econ Stat. 2016;98(1):42-56. https:// doi.org/10.1162/REST_a_00526.

32. Colorado Department of Revenue. https://www.colorado.gov/pacific/enforcement/ archived-med-medical-and-retail-cannabis-licensee-lists. (Accessed 3/15/2018).

33. Glass JR, Sproule BA, Herrmann N, Busto UE. Effects of 2-week treatment with temazepam and diphenhydramine in elderly insomniacs: a randomized, placebo-controlled trial. J Clin Psychopharmacol. 2018;28(2):182-188. https://doi.org/10.1097/ JCP.0b013e31816a9e4f.

34. Morin M, Koetter U, Bastien C, Ware JC, Wooten V. Valerian-hops combination and diphenhydramine for treating insomnia: a randomized placebo-controlled clinical trial. Sleep. 2005;28(11):1465-1471. https://doi.org/10.1093/sleep/28.11.1465.

35. Fitzgerald T, Vietri J. Residual effects of sleep medications are commonly reported and associated with impaired patient-reported outcomes among insomnia patients in the United States. Sleep Disord. 2015;2015:607148https://doi.org/10.1155/2015/ 607148.

36. Chung S, Youn S, Yi K, Park B, Lee S. Sleeping pill administration time and patient subjective satisfaction. J Clin Sleep Med. 2016;12(1):57-62. https://doi.org/10.5664/ jcsm.5394.

37. Haroutounian S, Ratz Y, Ginosar Y, et al. The effect of medicinal cannabis on pain and quality-of-life outcomes in chronic pain: a prospective open-label study. Clin $J$ Pain. 2016;32(12):1036-1043. https://doi.org/10.1097/AJP.0000000000000364.

38. Bubu OM, Brannick M, Mortimer J, et al. Sleep, cognitive impairment, and Alzheimer's disease: a systematic review and meta-analysis. Sleep. 2017;40(1) https://doi.org/10.1093/sleep/zsw032 zsw032.

39. Kang DW, Lee CU, Lim HK. Role of sleep disturbance in the trajectory of Alzheimer's Disease. Clin Psychopharmacol Neurosci. 2017;15(2):89-99. https://doi.org/10.9758/ cpn.2017.15.2.89.

40. Pillai JA, Leverenz JB. Sleep and neurodegeneration: a critical appraisal. Chest. 2017;151(6):1375-1386. https://doi.org/10.1016/j.chest.2017.01.002.

41. Lee K, Baron K, Soca R, Attarian H. The prevalence and characteristics of rem sleep without atonia (RSWA) in patients taking antidepressants. J Clin Sleep Med. 2016;12(3):351-355. https://doi.org/10.5664/jcsm.5582.

42. National Academies of Sciences, Engineering, and Medicine, Health and Medicine Division, Board on Population Health and Public Health Practice, Committee on the Health Effects of Marijuana. An evidence review and research agenda. Washington (DC): National Academies Press (US); 2017 Jan 12

43. Bonn-Miller MO, Babson KA, Vandrey R. Using cannabis to help you sleep: Heightened frequency of medical cannabis use among those with PTSD. Drug Alcohol Depend. 2014:136:162-165. https://doi.org/10.1016/j.drugalcdep.2013.12.008.

44. Chagas MHN, Eckeli AL, Zuardi AW, et al. Cannabidiol can improve complex sleeprelated behaviours associated with rapid eye movement sleep behaviour disorder in Parkinson's disease patients: a case series. J Clin Pharm Ther. 2014;39:564-566. https://doi.org/10.1111/jcpt.12179.

45. Piper BJ, Dekeuster RM, Beals ML, Lynn SL, Nichols SD, Abess AT. Substitution of medical cannabis for pharmaceutical agents for pain anxiety and sleep. $J$ Psychopharmacol. 2019;31(5):569-575.

46. Vigil JM, Stith SS, Diviant JP, Brockelman F, Keeling K, Hall B. Effectiveness of raw, natural medical Cannabis flower for treating insomnia under naturalistic conditions. Medicines. 2018;5(3):75. https://doi.org/10.3390/medicines5030075.

47. Stith SS, Vigil JMV. Federal barriers to Cannabis research. Science. 2016;352(6290):1182. https://doi.org/10.1126/science.aaf7450.

48. Mander BA, Winer JR, Walker MP. Sleep and human aging. Neuron. 2017;94(1):19-36. https://doi.org/10.1016/j.neuron.2017.02.004. 